\title{
Should 'fitness to practise' include safeguarding the reputation of the profession?
}

\author{
P. Affleck*1 and K. Macnish ${ }^{1}$
}

\section{In brief}

Highlights the risks that social media poses to dental professionals
Questions whether dental professionals should be reprimanded when there is no suggestion they have treated patients badly or will do so in the future.
Considers the relationship between reputation and fitness to practise.

Earlier this year a dental nurse was reprimanded by the GDC for a single comment on social media. The nurse subsequently admitted that the comment was unprofessional and offensive. However, the comment did not mention her status as a dental nurse, nor did it involve any of her patients. The nurse did breach GDC guidance and therefore, within the current system, a reprimand was appropriate. This case highlights the perils of social media but also shows how dental professionals are judged on whether their non-professional lives offend the public. Whether this is fair needs discussion.

\section{Introduction}

In July 2015 Nadia Armstrong, a dental nurse, posted the following message on Facebook: 'Sitting at a red light at ardoyne and of course they start and an the guy in front who was in the Orange order put it in reverse and took out about 10 of them yeooo up the SPB. ${ }^{1}$

This cryptic remark resulted in a complaint to the General Dental Council (GDC). The dental nurse was called before the GDC's Professional Conduct Committee (PCC) on a charge of unprofessional and offensive behaviour. The PCC found that the nurse's fitness to practise was impaired and issued a reprimand.

So what did this comment actually mean? It was made in connection to an Orange Order parade in Belfast, which had taken place the previous day. When this parade was prevented from passing a Catholic estate violence ensued and a car reversed into the crowd, injuring a teenage girl. ${ }^{1}$ The driver of the car was arrested on suspicion of attempted murder. The initials SPB seemingly stand for Shankill Protestant Boys, a Protestant marching band. The nurse's post was therefore praising an act of sectarian violence.

${ }^{1}$ University of Leeds, School of Dentistry, Worsley Building, Leeds, LS2 9JT

${ }^{*}$ Correspondence to: P Affleck

Email: p.a.affleck@leeds.ac.uk

Refereed Paper. Accepted 14 September 2016

DOI: 10.1038/sj.bdj.2016.812

${ }^{\circ}$ British Dental Journal 2016; 221: 545-546

\section{The dangers of social media}

Clearly this case is a cautionary tale regarding the dangers of social media. On sites such as Facebook it is very easy to make instant, illconsidered comments which may be electronically immortalised. Even if you only share your comments with a small circle of social media contacts, any one of them can take a screenshot and share it more widely. If a person makes a bigoted comment they may well be a bigot. But it is also possible that a single, ill-considered remark does not convey a person's character. Few of us can probably claim to have never made a prejudiced remark or comment, and even fewer to have never entertained a prejudiced thought. We may well be relieved that verbal utterances rarely persist in the way social media posts do and that our thoughts remain private.

Most people will remember the case of Walter Palmer, the Minnesota dentist who killed a lion called Cecil while on a hunting holiday in Zimbabwe. Palmer's hobby is killing large game animals and pictures of him with his kills can be seen at the, unfortunately named, site https://trophyhuntamerica. smugmug.com. The images that were used by the media, and in Tweets and Facebook posts, may well have originated on this site. Hunting large animals for pleasure and taking parts of their bodies as trophies strikes many people as distasteful if not outright immoral. However, while not being charged with any crime, Palmer provoked a storm of online abuse, with people posting his contact details online and encouraging him to commit suicide. ${ }^{2}$ There were protests outside his clinic and the care of patients was disrupted. Interestingly, the media never seemed to pass up an opportunity to highlight his profession.

The cases of Nadia Armstrong and Walter Palmer therefore highlight the danger of social media: text, images and knowledge can be widely shared and show you in a way that damages your reputation. It could be argued that social media revealed hidden parts of their characters. In the case of Armstrong, the suspicion was that her comment revealed her as a bigot. In Palmer's case that killing majestic animals for pleasure showed an aggressive and callous nature. Even if we accept that their actions did reveal their characters though, it does not necessarily follow that they are incompetent to practise professionally. At work, whatever that work is, we often have to put away personal considerations because we know we have a duty to behave in a particular way. To take a trivial example, many of us will be friendly at work with people that in our personal lives we would actively avoid. At work we are expected to function within a team.

\section{Scope of professional registration}

So why was the nurse's offensive comment, which made no reference to patients or dentistry, a matter for the GDC? The PCC concluded that the comment was approving an act of sectarian violence and therefore contravened the GDC's ninth Standard: 'You must ensure that your conduct, both at work and in your personal life, 
justifies patients' trust in you and the public's trust in the dental profession. ${ }^{3}$

Making such a sectarian comment could well lead to the public, especially its Catholic members, placing less trust in this individual nurse. By extension, it could also lead to less trust in the profession as a whole. The conclusion of the PCC was that, as the nurse's comment contravened the GDC's ninth Standard, her fitness to practise was impaired by reason of misconduct. ${ }^{1}$

Few would disagree that she behaved badly in posting the comment, which seemingly celebrated a violent act for being sectarian. She also clearly deviated from the GDC's Guidance on using social media: 'You should not post any information, including personal views, or photographs and videos, which could damage public confidence in you as a dental professional. ${ }^{4}$

Given these facts a reprimand would seem justified. However, following the guidance would suggest only posting the most innocuous comments/content that no one could judge inappropriate. What is posted is not judged on its own merits, but on whether it offends public opinion.

Should professional regulation extend so far beyond the dental practice? A plausible view is that the manner in which a professional treats their patients is what really counts and that in all other matters the professional should be treated like anyone else. However, that would involve redefining the professions, since part of what defines a profession is that they have ethical codes that 'demand more than conventional morality and law.5 As previously mentioned, the GDC's code requires even personal, non-work conduct to justify the public's trust in the dental profession.

\section{Fitness to practise}

So was the nurse's fitness to practise actually impaired? There did not seem to be any evidence that the nurse had treated, or would treat, Catholic patients any differently to Protestant ones. The committee actually accepted the nurse was a 'capable, caring and well-regarded dental professional.' But the Committee found:

'Your actions have placed the profession at real risk of being brought into disrepute. The Committee further considers that a finding of impairment is also needed in order to maintain public confidence in the GDC as regulator in light of the findings that the Committee has made.'

The implications of this finding are that actions in a person's non-work life which place the profession's reputation at risk, for whatever reason, means your fitness to practise is impaired, even if your work with actual patients is admirable.

\section{Maintaining public confidence}

An interesting question is whether the GDC should consider actions that do not have a direct bearing on an individual's professional duties. What is at issue here is the importance of character. The ability to control membership of a profession on the basis of character does make some sense. If the public see a professional behaving in a controversial or disreputable way, they may well place less trust in the profession. This is arguably what was motivating the linkage between Walter Palmer's killing of Cecil the lion and his work as a dentist. There is a core belief which extends throughout and beyond the profession to the effect that dental professionals are fundamentally good people, a belief which was shaken when a dentist was found to have killed a popular lion. However, unlike Nadia Armstrong, Walter Palmer was not reported for unprofessional behaviour. So what criteria should be used to determine if a professional's actions bring the profession into disrepute?

\section{What counts as disrepute}

Nadia Armstrong made a single, brief online comment that was regarded as placing the profession at real risk of being brought into disrepute. ${ }^{1}$ Now imagine a female dental nurse who was found to have cheated on her husband, having an affair with someone who is not one of her patients. Her character would be in question, her trustworthiness doubted, and yet it seems hard to imagine that she would be disciplined for this particular transgression should anyone complain to the GDC about her behaviour. The key distinction would seem to be public opinion and knowledge of the event, rather than the character of the professional.

Was it really fair to reprimand Nadia Armstrong? Her comment did not have a direct impact on her ability to practice reliably and fairly, as recognised by the PCC. Yes, she fell foul of the current guidance, but that guidance may need revision. An alternative is to agree with the findings of the PCC but to insist that therefore all moral failings have an impact on one's ability to practise, leading to the adulterous nurse being considered for her behaviour as well. Between these lies a third position, which is to identify particular moral failings that have an undisputed implication on the ability to practise, but if these are to be grounds for disciplinary procedures then they would need to be clearly spelled out.

Remaining with the adulterous nurse for a moment, imagine that the affair remains private and never enters the public's awareness. In this case no harm has been visited on the reputation of the profession. Now imagine the affair was with an MP and is discovered and splashed across the tabloids for a week, the papers never failing to mention the nurse's profession. In this latter case there may well be reputational damage to the profession, even though the actions of the nurse are identical in both instances. The point is that reputational damage is often a slave to fortune and the fickleness of what interests the public, rather than what is in the public interest. One concern is that worrying about reputation will distract from a focus on what really matters: the best interests of patients.

\section{Conclusion}

We argue that the GDC should not judge individual professionals on the basis of public perception of the profession's reputation. Judgments should be made on whether the public's wellbeing is threatened. So, if a dental professional receives a criminal conviction for what they do outside of their work, say for fraud or assault, it is right that the GDC reviews their case for any implications for their dental practice. However, it should not selectively police the conduct of professionals in their non-professional lives based on complaints from the public. There are probably things in all of our private lives, which, if brought to the attention of enough people, would offend someone. It should not be the role of the GDC to decide if those things are offensive enough to warrant bringing the profession into disrepute. For the sake of clarity, we agree with the PCC that Armstrong's comment was offensive and that it contravened current standards. However, we believe that the question at the heart of the decision to reprimand her should have been whether she treated all her patients with the respect they were due, not what she posted in a personal capacity on Facebook.

1. GDC. Professional Conduct Committee March 2016. General Dental Council. 2016. Available online at www. gdc-uk.org/Membersofpublic/Hearings/Determinations $\% 20$ 2016/ARMSTRONG\%20PCC\%20Determination\%20-\%20 March\%202016.pdf (accessed July 2016).

2. BDCwire. Walter Palmer killed Cecil the Lion. Then the Internet threatened to kill him. 2015. Available online at www.bdcwire.com/cecil-the-lion (accessed July 2016).

3. GDC. Standards for the dental team. General Dental Council. 2013. Available online at www.gdc-uk.org/dentalprofes sionals/standards/Pages/home.aspx (accessed July 2016).

4. GDC. Guidance on using social media. General Dental Council. 2016. Available online at www.gdc-uk.org/ Contactus/Pages/Social-media-at-the-GDC.aspx (accessed July 2016).

5. Cowton C. Accounting and the ethics challenge: Re-membering the professional body. Acc Bus Res 2009; 39: 177-189. 